\title{
Hydrogenation of Body-Centered-Cubic Titanium-Chromium Alloys Prepared by Mechanical Grinding
}

\author{
Nobuhiko Takeichi ${ }^{1}$, Hiroyuki T. Takeshita ${ }^{1, * 1}$, Toshio Oishi ${ }^{2}$, Tadashi Kaneko ${ }^{2}{ }^{* 2}$, \\ Hideaki Tanaka ${ }^{1}$, Tetsu Kiyobayashi ${ }^{1}$ and Nobuhiro Kuriyama ${ }^{1}$ \\ ${ }^{1}$ National Institute of Advanced Industrial Science and Technology, Ikeda 563-8577, Japan \\ ${ }^{2}$ Department of Materials and Engineering, Kansai University, Suita 564-8680, Japan
}

The C15 and C14 intermetallic $\operatorname{TiCr}_{2-x}(x=0,0.2$ and 0.5$)$ compounds were subjected to grinding in a high-energy ball mill. The $\mathrm{X}$-ray diffraction profiles showed that the crystal structure transformed from $\mathrm{C} 15$ and $\mathrm{C} 14$ to bcc after mechanical grinding for $57.6 \mathrm{ks}$. The hydrogenation properties of the $\operatorname{TiCr}_{2-x}(x=0,0.2$ and 0.5$)$ samples were examined by differential thermal analysis and pressure-composition isotherm measurements. The sample reacted with hydrogen at $5 \mathrm{MPa}$ and $523 \mathrm{~K}$ by maintaining the bcc structure. An higher hydrogen content was observed for the sample with the higher Ti content. The maximum hydrogen content of $\mathrm{TiCr}_{2.0}, \mathrm{TiCr}_{1.8}$ and $\mathrm{TiCr}_{1.5}$ was found to be about $0.32,0.36$ and $0.47 \mathrm{H} / \mathrm{M}$ at $313 \mathrm{~K}$, respectively, at $8 \mathrm{MPa}$.

(Received May 21, 2002; Accepted June 10, 2002)

Keywords: mechanical grinding, X-ray diffraction, titanium-chromium system, solid solution phase, bcc structure, Laves phase, hydrogen storage materials

\section{Introduction}

Recently, it has been reported that certain alloys with bcc structure can absorb a large amount of hydrogen. ${ }^{1-5)}$ Iba and Akiba reported that Ti-V-Mn and Ti-V-Cr alloys exhibited large hydrogen capacities ${ }^{1-3)}$ of over 2 mass $\%$. Okada et al. reported that a bcc phase, which is metastable at ambient temperatures in the Ti-Cr binary system, can be stabilized by the addition of third element such as $\mathrm{V}$. The Ti-Cr-V ternary alloys have high hydrogen capacity at room temperature. Especially, the Ti-5V-57.5Cr alloy with bec structure reversibly absorbed and desorbed 2.8 mass $\%$ hydrogen at $\left.313 \mathrm{~K}^{6}{ }^{6}\right)$

The bcc solid solution phase in the Ti-Cr binary system is a metastable phase at room temperature in the range from $63 \mathrm{~mol} \% \mathrm{Cr}$ to $66 \mathrm{~mol} \%$. $^{7)}$ Heat treatment followed by quenching is required to prepare a single phase sample of the bcc phase. However, it is difficult to obtain the single phase sample without addition of other elements, because Laves phases are simultaneously formed during quenching.

Both mechanical alloying (MA ${ }^{8-10)}$ and mechanical grinding $(\mathrm{MG})^{11,12)}$ are convenient and simple methods to prepare metastable materials. It has been reported that for intermetallic compounds such as $\mathrm{Ti}_{3} \mathrm{Ir}, \mathrm{V}_{3} \mathrm{Ga}$ and $\mathrm{Nb}_{3} \mathrm{Au}$, the original $\mathrm{Cr}_{3} \mathrm{Si}$ type structure can be transformed into the bcc structure that is stable at high-temperature by MG. ${ }^{13-16)}$ Based on this analogy, we expected to obtain a high-temperature phase in Ti-Cr system by MG. It is quite important to show an alternative technique to obtain such metastable phase for the preparation of hydrogen storage.

In this paper, we report that the $\mathrm{C} 15$ and $\mathrm{C} 14$ Laves structures transformed into bcc structure by MG. We also report on hydrogenation of bec solid solution alloys prepared by MG.

\footnotetext{
${ }^{* 1}$ Present address: Department of Materials and Engineering, Kansai University, Suita 564-8680, Japan.

${ }^{* 2}$ Undergraduate Student, Kansai University. Present address: Graduate Student, Osaka University.
}

\section{Experimental}

$\operatorname{TiCr}_{2-x}(x=0,0.2$ and 0.5$)$ alloy ingots were prepared by arc melting, and then crushed into a powder which passed through a $0.105 \mathrm{~mm}$ screen. The powder of each alloy was sealed in a stainless steel vial (SUS 304, inner volume: $250 \mathrm{ml}$ ) together with stainless steel balls (SUS 304, $4 \mathrm{~mm}$ in diameter) in a glove box under an Ar atmosphere in order to prevent alloys from oxidizing. The weight ratio of the balls to samples was maintained at 10:1. MG was performed using a high-energy planetary ball mill (BX254E Kurimoto, Ltd.) at a rotation speed of $12 \mathrm{rps}\left(73.6 \mathrm{~s}^{-1}\right)$. The hydrogen occlusion samples were prepared by hydrogenation-dehydrogenation of the samples made by MG. The hydrogen content of the samples was calculated using a volumetric method.

The constituent phases in the sample were examined by the X-ray diffraction (XRD) analysis using a $2 \theta-\theta$ powder diffractometer with $\mathrm{Cu} \mathrm{K} \alpha$ radiation. An analysis of the powder diffraction data collected between 10 and 120 degrees in $2 \theta$ at room temperature with 0.05 degree steps, was used in order to refine the crystal structures of the obtained alloys.

The hydrogenation properties of the samples were evaluated by differential thermal analysis (DTA) and pressurecomposition isotherm (PC-isotherm) measurement. In the DTA measurement of the samples, the temperature was increased from room temperature to $773 \mathrm{~K}$, and the temperature scanning rate upon heating and cooling was kept at $0.167 \mathrm{~K} / \mathrm{s}$. The PC-isotherms were measured with an automatic Sieverts'-type apparatus. The sample was put into a vessel, and then evacuated at $573 \mathrm{~K}$ for $7.2 \mathrm{ks}$ using a rotary vacuum pump. Hydrogen was gradually introduced into the vessel up to a pressure of $10 \mathrm{MPa}$, and then degassed at $623 \mathrm{~K}$ under vacuum for $1.8 \mathrm{ks}$. This process was repeated twice for the initial hydrogenation. Each equilibrium pressure at the respective hydrogen contents was determined at least $3 \mathrm{~h}$ after adding or removing hydrogen. The hydrogen absorptiondesorption properties were defined by the 3 rd cycle of the PC- 
isotherms.

\section{Results and Discussion}

Figure 1 shows the XRD profiles of the as-melt $\mathrm{TiCr}_{2-x}$ $(x=0,0.2$ and 0.5$)$ alloys. The profile of the $\mathrm{TiCr}_{2}$ alloy indicated the existence of the phases with the cubic $\mathrm{C} 15$ type structure and the hexagonal C14-type structure besides Si mixed into the sample for correction of diffraction angles. It was found that the constituent phases of the $\mathrm{TiCr}_{1.8}$ and $\mathrm{TiCr}_{1.5}$ samples were the $\mathrm{C} 15$ and $\mathrm{C} 14$ Laves phases as well as $\mathrm{TiCr}_{2}$. Therefore, these as-melt samples were composed of two Laves phases within the detection ability of our XRD instrument.

Figure 2 shows the XRD profile of the $\mathrm{TiCr}_{1.8}$ sample ground for $57.6 \mathrm{ks}$ and the profile of $\mathrm{TiCr}_{1.8}$ with bec structure simulated by Rietveld method. The diffraction peaks from the $\mathrm{C} 15$ and $\mathrm{C} 14$ Lave phases disappeared and only the peaks from the new phase were observed after MG. The sets of the new peaks agreed well with those corresponding to the interplanar spacing of the bcc structure. Since a solid solution region with bcc structure exists in the Ti-Cr phase diagram, ${ }^{7}$ ) we propose that this new phase is a solid solution phase with a

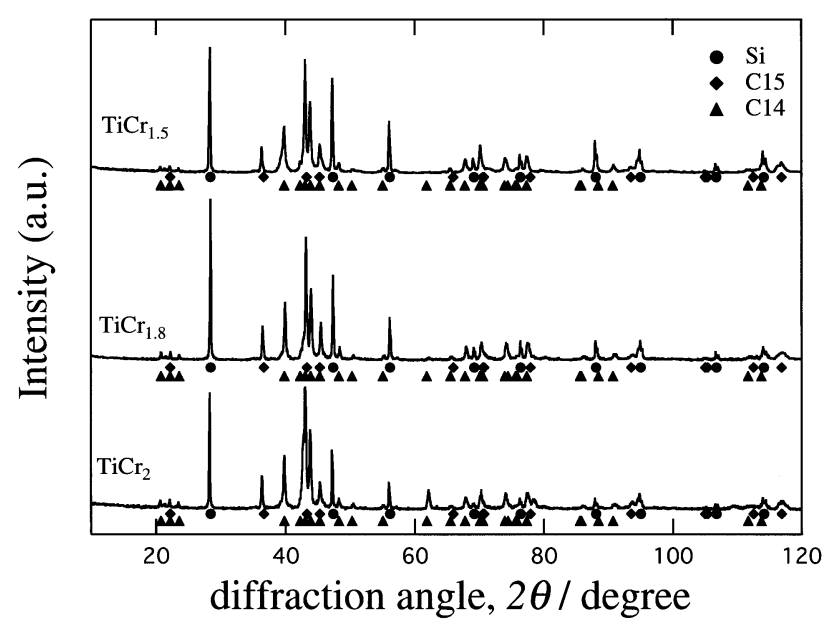

Fig. 1 The X-ray diffraction profiles of $\operatorname{TiCr}_{2-x}(x=0,0.2$ and 0.5$)$ alloys prepared by arc melting.

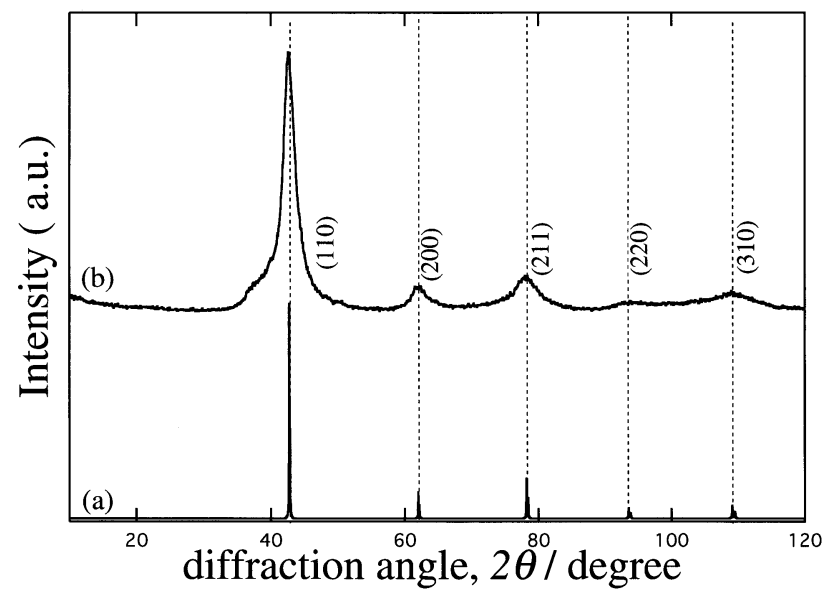

Fig. 2 A comparison of the X-ray diffraction profiles of (a) bcc structure simulated by Rietveld method with (b) the $\mathrm{TiCr}_{1.8}$ alloy prepared by MG for $57.6 \mathrm{ks}$. bcc structure. Figure 3 shows the XRD profiles of the $\mathrm{TiCr}_{2-x}$ $(x=0$ and 0.5$)$ samples ground for $57.6 \mathrm{ks}$ together with the profile of the $\mathrm{TiCr}_{1.8}$ sample ground for $57.6 \mathrm{ks}$. As well as the $\mathrm{MG} \mathrm{TiCr}_{1.8}$ sample, the XRD diffraction peaks observed for the two alloys were identified as those from the bcc phase. The results showed that MG also caused a phase transformation from the Laves phases to the bcc phase for these two samples. The X-ray diffraction peaks shifted to lower angles with increasing the Ti concentration in the sample, which indicates enlargement of the lattice constant of the bcc phase due to the substitution of the smaller atoms ( $\mathrm{Cr}$ ) by larger atoms (Ti).

Figures 4 and 5 show the DTA profiles measured under a hydrogen atmosphere for the samples prepared by MG and the XRD profiles for the samples after the DTA measurements, respectively. An exothermic peak was observed at $500-550 \mathrm{~K}$ for the 1 st cycle and no other peak appeared after repeating the heating and cooling in the range from room temperature to $773 \mathrm{~K}$. The XRD profile of the sample after the DTA measurement indicated that existence of the phase with bcc structure. Since the diffraction peaks shifted to lower angles compared with those of the original sample after the DTA measurement, the lattice constant was enlarged with respect to that of the original samples. These results indicate that hydrogenation occurred in the MG sample at 500-550 K during the 1 st cycle.

According to the above DTA measurement, we selected the

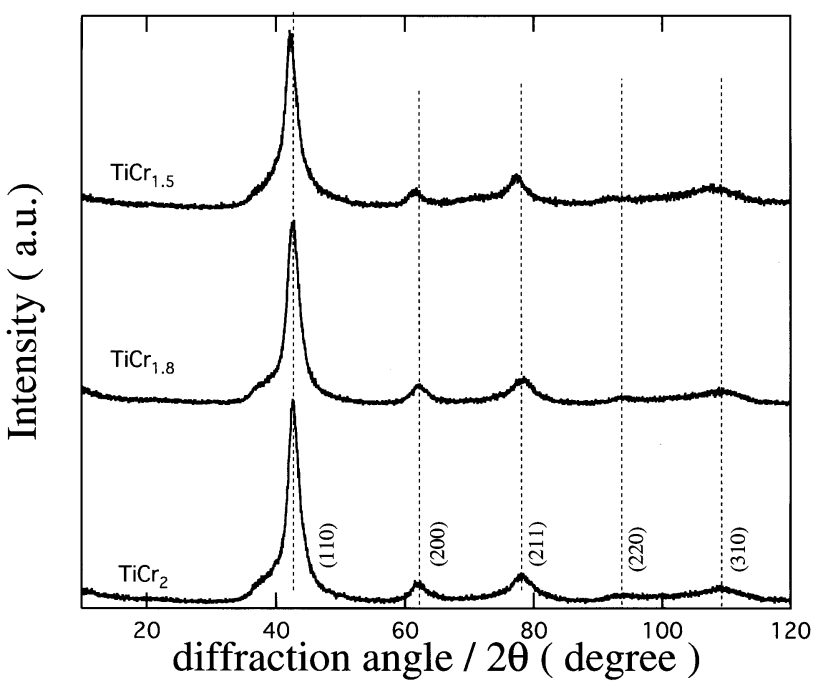

Fig. 3 The X-ray diffraction profiles of the $\mathrm{TiCr}_{2-x}(x=0,0.2$ and 0.5$)$ alloys prepared by MG.

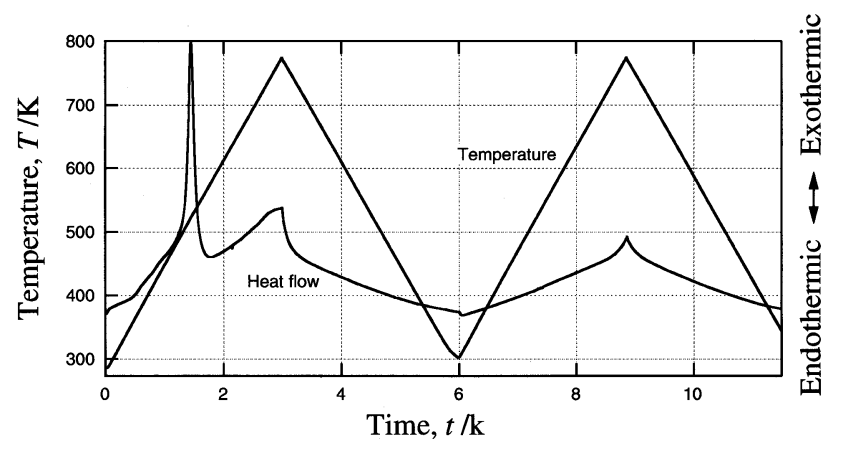

Fig. 4 Heat flow profile obtained by differential thermal analysis in $5 \mathrm{MPa}$ $\mathrm{H}_{2}$ atmosphere for the $\mathrm{TiCr}_{1.8}$ sample prepared by $\mathrm{MG}$. 


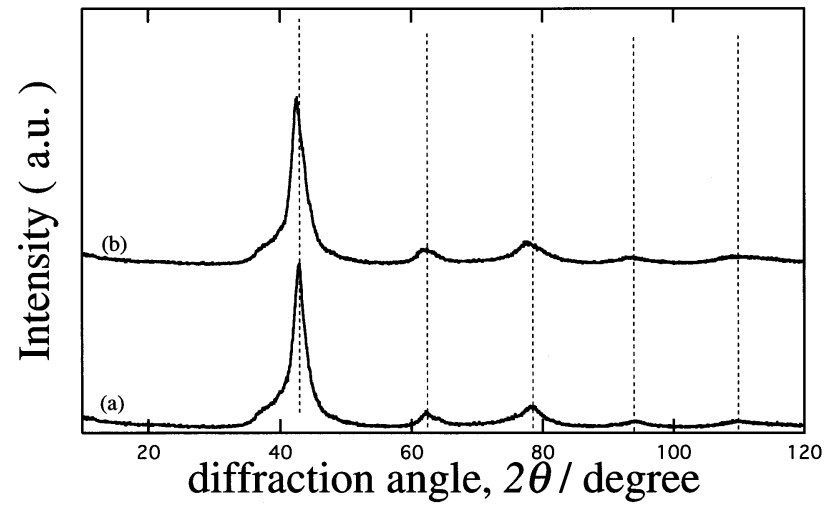

Fig. 5 The X-ray diffraction profiles of (a) the $\mathrm{TiCr}_{1.8}$ sample prepared by MG with (b) the $\mathrm{TiCr}_{1.8}$ sample prepared by $\mathrm{MG}$ after differential thermal analysis from room temperature to $773 \mathrm{~K}$ under $\mathrm{H}_{2}$ atmosphere.

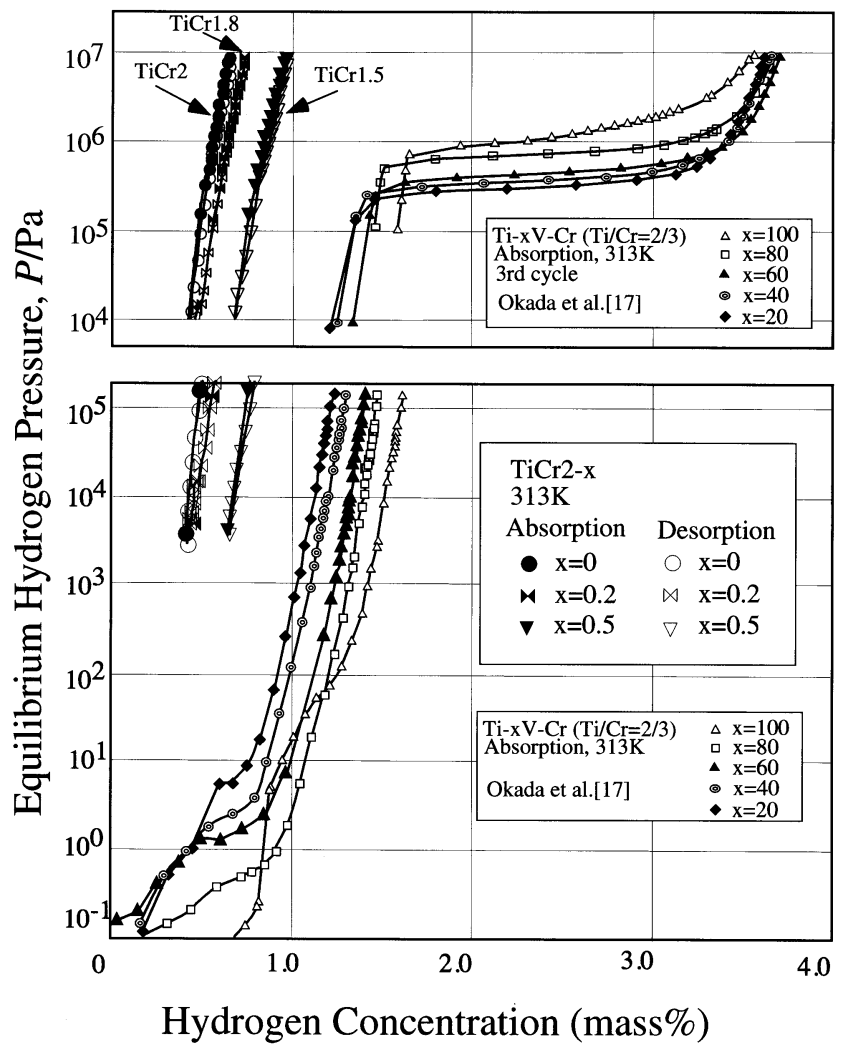

Fig. 6 The hydrogen pressure-composition-isotherms of the $\mathrm{TiCr}_{2-x}$ $(x=0,0.2$ and 0.5$)$ samples prepared by $\mathrm{MG}$ at $313 \mathrm{~K}$, together with the data reported by Okada et al. ${ }^{17)}$

condition of the activation treatment in this study; $573 \mathrm{~K}$ for the reaction temperature and $5 \mathrm{MPa}$ for the hydrogen pressure. After the activation treatments, the $\mathrm{PC}$-isotherms were measured at $313 \mathrm{~K}$. Figure 6 shows the PC-isotherms in the absorption-desorption process of the $\mathrm{TiCr}_{2-x}(x=0,0.2$ and 0.5 ) samples prepared by $\mathrm{MG}$, together with the data of $\mathrm{Ti}-\mathrm{V}-\mathrm{Cr}$ with bcc structure prepared by melting and heat treatment. ${ }^{17)}$ It is characteristic that all the PC-isotherms of the samples were significantly sloped. The equilibrium pressure of the samples increased with increasing $\mathrm{Cr}$ content at a given hydrogen content, and the hydrogen content increased with decreasing $\mathrm{Cr}$ content. The maximum hydrogen contents of $\mathrm{TiCr}_{2.0}, \mathrm{TiCr}_{1.8}$ and $\mathrm{TiCr}_{1.5}$ at $8 \mathrm{MPa}$ were $0.32,0.36$ and $0.47 \mathrm{H} / \mathrm{M}$ at $313 \mathrm{~K}$, respectively, where $\mathrm{H} / \mathrm{M}$ means the

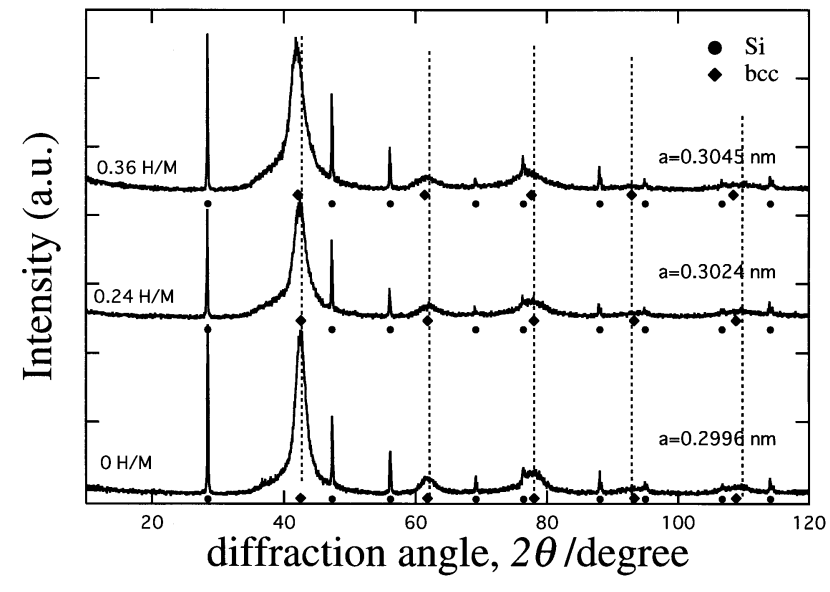

Fig. 7 The X-ray diffraction profiles of the hydrogen occlusion phase. These samples have hydrogen contents of $0,0.24$ and $0.36 \mathrm{H} / \mathrm{M}$.

atomic ratio of hydrogen to metal.

Figure 7 shows the XRD profiles of the hydrogen occlusion phase with hydrogen contents of $0,0.24$ and $0.36 \mathrm{H} / \mathrm{M}$. The XRD profiles indicated the existence of a phase with bcc structure along with Si mixed to the sample for correction of the diffraction angles, and the diffraction peaks shifted to lower angles compared with those of the original sample. The lattice constants calculated by the least square method for these samples were $0.2996,0.3024$ and $0.3045 \mathrm{~nm}$, respectively. The value continuously changed with the hydrogen content. Therefore, it is concluded that the samples prepared by MG form a solid solution phase with hydrogen up to $10 \mathrm{MPa}$ as determined in this study.

Okada et $a l .{ }^{17)}$ reported that the stable vanadium monohydride became unstable by adding the other element. This PC-isotherm showed two hydrogen occlusion phases with low and high contents coexisted in the hydrogenated sample. One can find that behavior of the sample prepared by MG is quite different from that of the alloys prepared by melting followed by heat treatment. From the Fig. 6 and Fig. 7, the sample prepared by MG exhibited the hydrogenation behavior as a continuous hydrogen solid solution, but several orders of magnitude higher hydrogen pressures. Moreover, the sample prepared by MG did not show much hydrogen absorption such as 3 mass \% with the phase transformation, which was observed in the previous paper. ${ }^{17)}$ At the present stage, it is difficult to give an appropriate explanation for the instability of the hydrogenation of the samples prepared by MG. However, it is interesting to examine the local atomic structure of the sample prepared by MG. We plan to measure the diffraction profile using transmission electron microscopy (TEM) and neutron diffraction. Further work is now in progress.

In conclusion, the structural change from $\mathrm{C} 15$ and $\mathrm{C} 14$ to bcc was found after mechanical grinding of the $\mathrm{TiCr}_{2-x}$ $(x=0,0.2$ and 0.5$)$ alloys. As far as we know, this is the first example of a phase transition from the Laves phases to bcc structure phase by mechanical grinding. The samples with the bcc structure reacted with hydrogen at $573 \mathrm{~K}$ under $5 \mathrm{MPa}$ of hydrogen atmosphere by maintaining bcc structure. This behavior is different from some bcc alloys with a high hydrogen storage capacity which indicate a 2 step hydride formation like the V-H system. The maximum hydrogen contents of 
$\mathrm{TiCr}_{2.0}, \mathrm{TiCr}_{1.8}$ and $\mathrm{TiCr}_{1.5}$ were estimated to be about 0.32 , 0.36 and $0.47 \mathrm{H} / \mathrm{M}$ at $313 \mathrm{~K}$, respectively, under an $8 \mathrm{MPa}$ hydrogen atmosphere.

\section{REFERENCES}

1) H. Iba and E. Akiba: J. Alloys Compd. 231 (1995) 508-512.

2) H. Iba and E. Akiba: J. Alloys Compd. 253-254 (1997) 21-24.

3) E. Akiba and H. Enoki: Materia Japan 37 (1998) 645, in Japanese.

4) E. Akiba and H. Iba: Intermetallic 6 (1998) 461-470.

5) T. Kabutomori, H. Takeda, Y. Wakisaka and K. Ohnishi: J. Alloys Compd. 231 (1995) 528-532.

6) M. Okada, T. Kuriiwa, T. Tamura, H. Takamura and A. Kamegawa: Metals and Materials International 7 (2001) 67-72.

7) T. B. Massalski (ed.): Binary Alloy Phase Diagrams, 2nd Edition, (ASM International, 1990) pp. 2924-2927.
8) C. C. Koch, O. B. Cavin, C. G. McKamey and J. O. Scarbrough: Appl. Phys. Lett. 43 (1983) 1017-1019.

9) R. B. Schwarz: Mater. Sci. Eng.: 97 (1988) 71-78.

10) R. B. Schwarz and C. C. Koch: Appl. Phys. Lett. 49 (1986) 146-148.

11) A. E. Ermakov, E. E. Yurchikov and V. A. Barnicov: Fiz. Met. Metalloved. 52 (1981) 1184-1193.

12) A. E. Ermakov, E. E. Yurchikov and V. A. Barnicov: Fiz. Met. Metalloved. 53 (1982) 302-306.

13) V. P. Balema, A. O. Pecharsky and V. K. Pecharsky: J. Alloys Compd. 307 (2000) 184-190.

14) L. M. Di and H. Bakker: J. Phys.: Condens. Matter 3 (1991) 3427-3432.

15) L. M. Di and H. Bakker: J. Phys.: Condens. Matter 3 (1991) 9319-9326.

16) E. Hellsteern, L. Schultz, R. Bormann and D. Lee: Appl. Phys. Lett. 53 (1988) 1399-1401.

17) M. Okada, T. Kuriiwa, T. Tamura, H. Takamura and A. Kamegawa: J. Alloys Compd. 330-332 (2002) 511-516. 